\title{
Effect of previous vaginal delivery on success of trial of labor in women with one previous lower segment caesarean section: a prospective study
}

\author{
Ganitha G. ${ }^{1 *}$, Lavanya S. G. ${ }^{1}$, Balaji Arumugam ${ }^{2}$
}

\begin{abstract}
${ }^{1}$ Department of Obstetrics and Gynaecology, Tagore Medical College and Hospital, MGR Medical University, Rathinamangalam, Chennai-127, Tamilnadu, India

${ }^{2}$ Department of Community Medicine, Tagore Medical College and Hospital, MGR Medical University, Rathinamangalam, Chennai-127, Tamilnadu, India
\end{abstract}

Received: 15 September 2016

Accepted: 19 September 2016

\author{
*Correspondence: \\ Dr. G. Ganitha, \\ E-mail: drgganitha77@gmail.com
}

Copyright: () the author(s), publisher and licensee Medip Academy. This is an open-access article distributed under the terms of the Creative Commons Attribution Non-Commercial License, which permits unrestricted non-commercial use, distribution, and reproduction in any medium, provided the original work is properly cited.

\section{ABSTRACT}

Background: Vaginal birth after caesarean (VBAC) has many advantages but failed trial of labor after caesarean (TOLAC) has increased morbidity and mortality. The objective of this study is to determine the influence of previous vaginal delivery on the success of TOLAC.

Methods: A prospective study was conducted on 250 women with history of one previous LSCS who underwent TOLAC. They were divided into two groups: Group 1 which included 184 women with previous LSCS and no vaginal delivery, group 2 included 66 women with previous LSCS and vaginal delivery before or after LSCS. Group 2 was further subdivided into group 2A-34 women with vaginal delivery before LSCS, group 2B-32 women with vaginal delivery after LSCS. The maternal outcome in terms of success rate of VBAC, scar dehiscence and uterine rupture was compared among the study groups. Chi square test was used for statistical analysis.

Results: The VBAC success rate of group 1, group 2A and group 2B was 70.7\%, 70.6\% and 100\% respectively. The VBAC success rate of women with history of vaginal delivery after LSCS (Group 2B) was significantly higher than those with no vaginal delivery (Group 1) $(\mathrm{p}=0.001)$ and women with vaginal delivery before LSCS (Group 2A) $(\mathrm{p}=0.003)$. The VBAC success rate of women with history of vaginal delivery before LSCS was not significantly higher than that of women with previous LSCS and no vaginal delivery $(p=0.99)$.

Conclusions: History of prior VBAC is a strong positive prognostic indicator for the success of TOLAC.

Keywords: Vaginal birth after caesarean, Trial of labor after caesarean, Prior vaginal birth

\section{INTRODUCTION}

Over the last few decades the spectrum of indications for caesarean delivery has been broadening. This has led to an increase in primary caesarean sections and consequently repeat caesarean deliveries. ${ }^{1}$ The caesarean delivery rate all over the world varies from $10 \%$ to $40 \%{ }^{2}$ In 2007, nearly one third $(32 \%)$ of all births were caesarean deliveries in the U.S. ${ }^{3}$ To bring down the rising caesarean delivery rate, the ACOG recommended that women with a prior LSCS should be given trial of labour after excluding contraindications. ${ }^{4}$
Successful vaginal birth after caesarean (VBAC) is associated with decreased hospital stay, less expenses and decreased maternal mortality and morbidity. ${ }^{4-7}$ However failed trial of labour after caesarean (TOLAC) resulting in repeat caesarean section or rupture uterus is associated with more maternal and fetal morbidity, mortality. ${ }^{8}$ The incidence of endometritis, scar dehiscence, uterine rupture, requirement for more units of blood transfusion, hysterectomy, PPH, bowel and bladder injuries, postpartum fever was higher in the failed TOLAC group than women undergoing elective repeat caesarean section (ERCS) or successful VBAC. ${ }^{8-13}$ 
Even though the risk of uterine rupture is small (0.5$0.9 \%$ ), most obstetricians are reluctant to give TOLAC because of the associated significantly high morbidity, mortality and difficulty in assessing the scar integrity before attempting TOL. ${ }^{8}$ Therefore, assessment of prognostic factors that influence the success or failure of TOL is of paramount importance before deciding the mode of delivery in women with prior LSCS.

The purpose of this study is to determine the influence of previous vaginal delivery before or after the previous LSCS on the success of TOLAC, scar dehiscence and uterine rupture following TOL in women with previous one LSCS.

\section{METHODS}

This prospective study was conducted in a tertiary care teaching hospital over a period of 18 months. Ethical committee clearance was obtained before starting the study. 250 women with previous one LSCS and uncomplicated term pregnancy (37-42 weeks), admitted to the antenatal ward or labor ward were chosen by simple random sampling method, after ruling out contraindications for vaginal delivery based on ACOG recommendations. Only women with singleton vertex presentation with no obstetric complication or medical disorders were included in the study. Women with more than one previous LSCS, classical caesarean section, history of uterine rupture, myomectomy or hysterotomy were excluded from the study. Women with Intra uterine demise, fetal and placental anomalies were also excluded.

All the women included in the study were counseled about the risks and benefits of TOL and written consent was taken from them. A detailed history including age, parity, number of vaginal deliveries prior to this pregnancy, the indication for LSCS and any intra operative, postoperative complications were recorded. Menstrual history was noted to ascertain the period of gestation. In women with history of previous vaginal birth, the order of vaginal delivery was noted i.e., whether the vaginal delivery was before or after the caesarean delivery. Accordingly, the study population was divided into two groups. Group 1 included women with previous LSCS and no history of vaginal delivery, group 2 included women with previous LSCS and history of vaginal delivery before or after LSCS. Group 2 was further subdivided into group 2A-women with history of vaginal delivery before LSCS, group 2B-women with history of vaginal delivery after LSCS (Figure 1).

A thorough general physical, systemic and obstetric examination was done. Per abdomen examination was done to note the period of gestation, to rule out any mal presentation and to estimate the expected fetal weight. Per vaginal examination was done to note the dilatation and effacement of cervix, station of vertex and adequacy of pelvis for vaginal delivery. Routine investigations were done. Ultrasonogram was done to know the fetal maturity, liquor amount, placental localization and to rule out fetal anomalies.

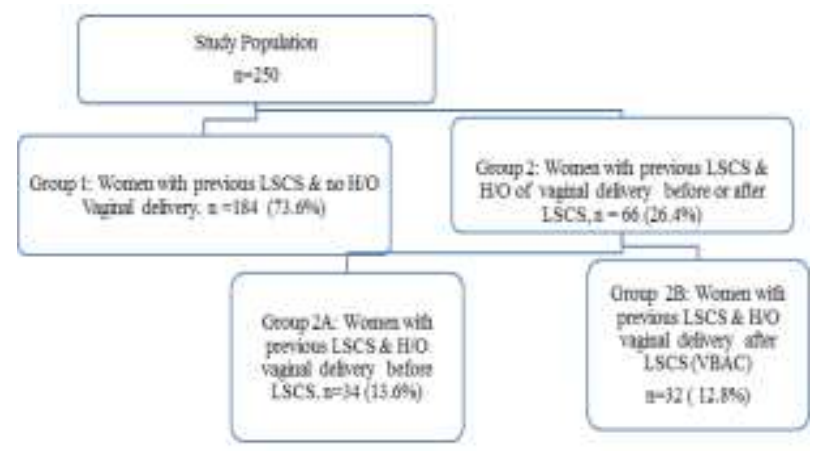

Figure 1: Distribution of study population.

During labor, patients were carefully monitored for any signs of impending rupture. Electronic CTG was used whenever possible. Progress of labor was noted by periodical per abdominal and per vaginal examination. Labor was accelerated with artificial rupture of membranes or oxytocin in few cases. Ventouse/forceps was used whenever indicated. Women who had failed TOL underwent repeat caesarean section due to various indications or for suspected rupture.

\section{Statistical analysis}

Information was collected in a structured proforma. Data was entered in MS Office Excel format and statistical analysis was performed using SPSS software (version 20). The success of VBAC, incidence of scar dehiscence, scar rupture and instrumental delivery was compared among the study groups. Data was analyzed using mean, standard deviation, percentage and chi square test. The values were compared at 0.05 level of significance.

\section{RESULTS}

Among the 250 women with history of one previous LSCS and undergoing TOL, 186 women had successful VBAC while 64 women underwent repeat LSCS due to various reasons.

The mean age of the study group was $24.11 \pm 3.7$ years. There was no significant difference in the mean age of women with no history of previous vaginal delivery and those with history of previous vaginal delivery (group 1mean age: $23.8 \pm 3.74$, group 2-mean age: $24.8 \pm 3.72$ ).

The mean gravidity of the 250 women was $2.46 \pm 0.72$. $88 \%$ of women in group 1 were second gravida and $75.8 \%$ of women in group 2 were third gravida.

The overall VBAC success rate in the study was $74.4 \%$. Among the 184 women in group 1, 130 women achieved VBAC (70.7\%). Out of 66 women in group 2, 56 women had successful VBAC (84.8\%). 
The success of VBAC in women with history of vaginal delivery before LSCS (group 2A) and after LSCS (group 2B) was $70.6 \%$ and $100 \%$ respectively.

Tables 1 and 2 show that women with history of prior vaginal delivery (group 2) have significantly more chances of successful VBAC in comparison with those who have had no prior vaginal delivery (group 1) $\left(x^{2}=4.42, p=0.035\right)$.

However, women with history of vaginal delivery prior to LSCS (group 2A) do not have significantly higher VBAC success rate when compared to women with no history of previous vaginal delivery (group 1$)\left(x^{2}=0.000, p=0.99\right)$.

Table 1: VBAC success rate in relation to history of previous vaginal delivery.

\begin{tabular}{|c|c|c|c|c|}
\hline \multirow[t]{2}{*}{$\begin{array}{l}\text { Outcome } \\
\text { of } \\
\text { TOLAC }\end{array}$} & \multicolumn{2}{|c|}{$\begin{array}{l}\text { Group } 1 \\
\text { (women with } \\
\text { previous LSCS } \\
\text { and no H/O } \\
\text { vaginal } \\
\text { delivery), } \mathbf{n = 1 8 4}\end{array}$} & \multicolumn{2}{|c|}{$\begin{array}{l}\text { Group } 2 \\
\text { (women with } \\
\text { previous LSCS and } \\
\text { H/O vaginal } \\
\text { delivery before or } \\
\text { after LSCS), } n=66\end{array}$} \\
\hline & No. of cases & $\%$ & No. of cases & $\%$ \\
\hline $\begin{array}{l}\text { Successful } \\
\text { VBAC }\end{array}$ & 130 & 70.7 & 56 & 84.8 \\
\hline $\begin{array}{l}\text { Failed } \\
\text { TOL- } \\
\text { LSCS }\end{array}$ & 54 & 29.3 & 10 & 15.2 \\
\hline
\end{tabular}

$\mathrm{x}^{2}=4.42, \mathrm{p}=0.035$

Table 2: VBAC success rate in relation to history of order of previous vaginal delivery.

\begin{tabular}{|c|c|c|c|c|}
\hline \multirow{3}{*}{$\begin{array}{l}\text { Outcome } \\
\text { of } \\
\text { TOLAC }\end{array}$} & \multicolumn{4}{|c|}{$\begin{array}{l}\text { Group } 2 \text { (women with previous LSCS } \\
\text { and H/O vaginal delivery before or } \\
\text { after LSCS), } n=66\end{array}$} \\
\hline & \multicolumn{2}{|c|}{$\begin{array}{l}\text { Group } 2 \mathrm{~A} \\
\text { (women with } \\
\text { previous LSCS } \\
\text { and H/O vaginal } \\
\text { delivery before } \\
\text { LSCS), } \mathrm{n}=\mathbf{3 4}\end{array}$} & \multicolumn{2}{|c|}{$\begin{array}{l}\text { Group 2B } \\
\text { (women with } \\
\text { previous LSCS } \\
\text { and H/O vaginal } \\
\text { delivery after } \\
\text { LSCS), } \mathbf{n = 3 2}\end{array}$} \\
\hline & No of cases & $\%$ & No of cases & $\%$ \\
\hline $\begin{array}{l}\text { Successful } \\
\text { VBAC }\end{array}$ & 24 & 70.6 & 32 & 100 \\
\hline $\begin{array}{l}\text { Failed } \\
\text { TOL- } \\
\text { LSCS }\end{array}$ & 10 & 29.4 & 0 & 0 \\
\hline
\end{tabular}

In the present study, all women having history of prior VBAC had successful VBAC in the current pregnancy also. The association of history of prior VBAC (group $2 \mathrm{~B}$ ) is extremely significant in comparison to both women with history of vaginal delivery prior to LSCS (group 2A) $\left(\mathrm{x}^{2}=8.923, \mathrm{p}=0.003\right)$ and women with no history of vaginal delivery (group 1) $\left(x^{2}=11.005\right.$, $\mathrm{p}=0.001)$. The overall VBAC success rate of women with history of prior vaginal delivery is mainly contributed by the success rate of women with history of prior VBAC. Therefore, though history of VBAC is associated with significantly high success of TOLAC, the same cannot be applied for women with history of prior vaginal delivery before LSCS.

Table 3 shows that out of the 250 women who underwent TOLAC, there were five cases of uterine rupture $(2 \%)$. All the five cases belonged to group 1. One of the women who had uterine rupture had to undergo subtotal hysterectomy. Scar dehiscence was seen in seven women. The incidence of scar dehiscence in group 1 (3.3\%) was not statistically significant in comparison to group 2 $(1.5 \%)\left(x^{2}=0.092, p=0.0762\right)$. There were three cases of broad ligament hematoma in group 1, one case of colporrhexis in group2 and one case of bladder injury in group 1. Forceps or ventouse extraction was used in 19 cases in group 1 and 3 cases in group 2 (group $2 \mathrm{~A}=3$, group $2 \mathrm{~B}=$ nil). The incidence of instrumental delivery in both groups was statistically not significant $(\mathrm{p}=0.2)$. There were no cases of $\mathrm{PPH}$, placental abnormalities or maternal mortality in the study.

Table 3: Incidence of scar dehiscence and scar rupture in the study groups.

\begin{tabular}{|c|c|c|}
\hline \multirow{2}{*}{ Outcome } & \multicolumn{2}{|c|}{ Number of cases } \\
\hline & Group 1 & Group 2 \\
\hline Scar dehiscence & $6(3.3 \%)$ & $1(1.5 \%)$ \\
\hline Uterine rupture & $5(2.7 \%)$ & 0 \\
\hline
\end{tabular}

\section{DISCUSSION}

Over the last few years, with the increase in caesarean delivery rates, obstetricians are encountering more and more pregnant women with previous LSCS. One of the measures suggested to bring down the caesarean delivery rate is to encourage vaginal delivery in women with previous LSCS.

The ACOG has laid down recommendations for TOLAC and several studies have recommended TOL in properly selected cases. ${ }^{4,6-8,12,14,15}$ As the TOLAC rates increased, the caesarean rates decreased but the number of reports of uterine rupture and other complications during TOLAC increased.

Many studies have shown that maternal and fetal morbidity, mortality is higher in failed TOLAC than ERCS. ${ }^{8-13}$ Mc Mahon et al found that maternal morbidity is lowest in women who have successful VBAC $(0.2 \%)$, higher in women who undergo ERCS $(0.8 \%)$ and highest in women who have failed TOL $(3.3 \%) .{ }^{11}$ Such reports and medico legal issues have raised concerns about the safety of TOLAC, which deter the obstetricians from the practice of TOLAC. However, the benefits of TOLAC leading to successful VBAC outweigh the risks when cases are properly assessed and selected before allowing 
for TOL. This has led to a search for prognostic factors that could influence the success of TOLAC.

The overall success rate of VBAC in our study was $74.4 \%$. The VBAC success rates in other studies ranged from $59 \%-91 \%$ with most of them reporting a rate of $60 \%-80 \%$. $^{6,14-20}$

In the present study we found that women with history of previous vaginal delivery had a higher success rate of VBAC (84.8\%) compared to women who did not have one. This is compared with other studies as shown in Table 4. ${ }^{9,14,15,21-24}$

Table 4: VBAC success rates following TOLAC in women with history of vaginal delivery versus women with no history of vaginal delivery-comparison with other studies.

\begin{tabular}{|lll|}
\hline Studies & $\begin{array}{l}\text { History of } \\
\text { vaginal } \\
\text { delivery }\end{array}$ & $\begin{array}{l}\text { History of } \\
\text { no vaginal } \\
\text { delivery }\end{array}$ \\
\hline Present study & $84.8 \%$ & $70.7 \%$ \\
\hline Gupta S et al & $64.28 \%$ & $58.7 \%$ \\
\hline Balachandran et al $^{21}$ & $76.8 \%$ & $41 \%$ \\
\hline Jinturkar et al $^{22}$ & $65.6 \%$ & $42.7 \%$ \\
\hline Jani et al $^{15}$ & $60 \%$ & $20 \%$ \\
\hline Chaudhari et al & $62.5 \%$ & $43.1 \%$ \\
\hline Shakthi et al & $100 \%$ & $71.4 \%$ \\
\hline Landon et al $^{24}$ & $87 \%$ & $61 \%$ \\
\hline
\end{tabular}

However in the above studies while interpreting the VBAC success rates for women with history of previous vaginal delivery, the success rate of women with history of prior VBAC and history of vaginal delivery before LSCS has not been evaluated separately. In our study, the higher success rate of VBAC seen in women with history of previous vaginal delivery was mainly contributed by women with history of prior VBAC.

VBAC success rate of women with history of vaginal delivery before LSCS was not statistically significant from women with no history of vaginal delivery. However, the VBAC success rate was extremely significant for women with history of prior VBAC.

In contrast to our study, Doshi Haresh et al, TessmerTuck et al, Park et al found that history of prior vaginal delivery before or after LSCS was associated with a significantly higher VBAC rate. ${ }^{17,18,25}$

A metaanalyasis of 13 retrospective cohort studies by Guise et al in reported a consistently high likelihood of VBAC in women with prior history of vaginal delivery. ${ }^{26}$ Women with a prior VBAC were 3-7 times more likely to have subsequent VBAC. A cohort study by Mercer et al shows that the chances of VBAC increased with each prior VBAC. Women with $0,1,2,3$ and 4 or more prior
VBAC had likelihood of subsequent VBAC of 63.3, 87.6, $90.9,90.6$ and $91.6 \%$ respectively. $^{27}$

Hendler and Bujold have done a similar study on larger scale with 2204 patients. They compared the success of TOL among women who had a previous caesarean section and no vaginal delivery, women who had a vaginal delivery before LSCS and women with prior VBAC. The rate of successful TOL was $70.1 \%, 81.8 \%$ and $93.1 \%$ respectively. They concluded that a prior vaginal delivery, particularly a prior VBAC was associated with a higher rate of successful TOL when compared with patients with no prior vaginal delivery. ${ }^{28}$

Caughey et al studied the effect of previous vaginal delivery on TOLAC of 800 women with history of one previous caesarean section and one previous vaginal delivery. They found that women whose most recent delivery was vaginal had a higher VBAC rate than those whose most recent delivery was caesarean. ${ }^{29}$

In accordance with the findings of our study, Gyamfi et al, Merwe et al, Birara et al and Gupta et al have reported significantly higher VBAC rates with history of prior VBAC but not with history of prior vaginal delivery before LSCS. ${ }^{2,9,20,30}$

In their analysis, Gyamfi et al found that patients with history of previous VBAC were seven times more likely to have subsequent VBAC. Those with the history of previous normal spontaneous vaginal delivery before LSCS were not likely to have a higher successful VBAC rate when the other variables were controlled. ${ }^{30}$

Van der Merwe et al conducted an analysis of TOL in 389 women who had a previous caesarean section and previous vaginal delivery. $86 \%$ of these women had VBAC. Of the women who had a previous VBAC, $91.1 \%$ delivered vaginally and $63.7 \%$ of those who did not have VBAC delivered vaginally. $61.6 \%$ women who did not have a previous vaginal delivery had successful VBAC. They found that whereas a previous vaginal delivery and a previous VBAC significantly increased the chances of VBAC, the difference remains significant only for the latter group on multivariable analysis. ${ }^{20}$

Birara et al found that women with prior successful VBAC had significantly higher chance of subsequent VBAC. They did not find significant relationship between VBAC success and past vaginal delivery before previous caesarean section. ${ }^{2}$ Gupta et al also did not find any correlation between history of previous vaginal delivery and success of VBAC. ${ }^{9}$

In our study, the incidence of uterine rupture and scar dehiscence was $2 \%$ and $2.8 \%$ respectively which was higher in comparison to other studies (Table 5). ${ }^{28,31}$ ACOG has reported a risk of $0.5 \%-0.9 \%$ chances of uterine rupture during TOLAC. ${ }^{8}$ 
Table 5: Incidence of uterine rupture in women with history of vaginal delivery and women with no history of vaginal delivery during TOLAC-comparison with other studies.

\begin{tabular}{|c|c|c|c|}
\hline \multirow{2}{*}{ Study } & \multirow{2}{*}{$\begin{array}{l}\text { No H/O } \\
\text { previous } \\
\text { vaginal } \\
\text { delivery }\end{array}$} & \multicolumn{2}{|c|}{$\begin{array}{l}\text { H/O previous } \\
\text { vaginal delivery }\end{array}$} \\
\hline & & $\begin{array}{l}\text { Prior to } \\
\text { LSCS }\end{array}$ & $\begin{array}{l}\text { Prior } \\
\text { VBAC }\end{array}$ \\
\hline Present study & $2.7 \%$ & $0 \%$ & $0 \%$ \\
\hline $\begin{array}{l}\text { Hendler et al } \\
\text { study }^{28}\end{array}$ & $1.5 \%$ & $0.5 \%$ & $0.3 \%$ \\
\hline Zelop et $\mathrm{al}^{31}$ & $1.1 \%$ & \multicolumn{2}{|c|}{$0.2 \%$} \\
\hline
\end{tabular}

According to Hendler and Bujold, a prior VBAC was associated with an increased rate of uterine rupture and scar dehiscence. ${ }^{28}$ This is in contrast to a study conducted by Zelop et al. ${ }^{31}$ They studied the effect of previous vaginal delivery on the risk of uterine rupture during a subsequent TOLAC. They concluded that women with a prior vaginal delivery had a substantially lower risk of uterine rupture than women without a prior vaginal delivery. ${ }^{31}$ In our study, we did not find a significant association between previous vaginal delivery and the risk of uterine rupture during a subsequent TOLAC $(\mathrm{p}=0.4)$. However, the incidence of scar dehiscence and scar rupture in our study is not sufficient to conclude the effect of previous vaginal delivery on the risk of uterine rupture during subsequent TOL. A larger population study or multicentric trials may be conducted for further evaluation.

\section{CONCLUSION}

Even though, there have been claims on the safety of VBAC, the maternal and fetal morbidity, mortality associated with a failed TOL or rupture uterus can deter obstetricians to choose a case for TOLAC. However, knowledge of the prognostic factors can be used to fairly predict the success of TOL. History of prior VBAC rather than history of prior vaginal delivery before LSCS is an important positive prognostic factor for predicting VBAC.

Funding: No funding sources

Conflict of interest: None declared

Ethical approval: The study was approved by the Institutional Ethics Committee

\section{REFERENCES}

1. Mittal S, Pardeshi S, Mayadeo N, Mane J. Trends in Caesarean Delivery: Rate and Indications. J Obstet Gynecol India. 2014;64(4):251-4.

2. Birara M, Gebrehiwot Y. Factors associated with success of vaginal birth after one caesarean section (VBAC) at three teaching hospitals in Addis Ababa, Ethiopia: a case control study. BMC Preg Childbirth. 2013;13:31.
3. Menacker F, Hamilton BE. Recent trends in caesarean delivery in the United States. NCHS data brief, no 35. Hyattsville, MD: National Center for Health Statistics. 2010. Available at http://www.cdc.gov/nchs/products/databriefs/db35.ht m. Accessed 15 September 2016.

4. Vaginal birth after previous caesarean delivery. ACOG Practice Bulletin No. 54. Obstet Gynecol 2004;104:203-12.

5. Obara H, Minakami H, Koike T, Takamizawa S, Matsubara S, Sato I. Vaginal birth after caesarean delivery: results in 310 pregnancies. J Obstet Gynaecol Res. 1998;24(2):129-34.

6. Gupta P, Jahan I, Gelabhai RJ. Is vaginal delivery safe after previous lower segment caesarean section in developing country? Niger Med J. 2014;55(3):260-5.

7. Chhabra S, Arora G. Delivery in women with previous caesarean section. J Obstet Gynecol India. 2006;56:304-7.

8. American College of Obstetricians and Gynecologists. Practice Bulletin: Clinical management guidelines for obstetriciangynecologists. Vaginal birth after previous caesarean delivery. Obstet Gynecol. 2010;116:450-63.

9. Gupta S, Jeeyaselan S, Guleria R, Gupta A. An observational study of various predictors of success of vaginal delivery following a previous caesarean section. J Obstet Gynaecol India. 2014;64(4):260-4.

10. Rossi CA, D'Addario V. Maternal morbidity following a trial of labor after caesarean section vs elective repeat caesarean delivery; a systematic review with meta-analysis. Am J Obstet Gynecol. 2008;199:224-31.

11. McMahon MJ, Luther ER, Bowes WA. Comparison of a trial of labor with an elective second caesarean section. N Engl J Med. 1996;335:689-95.

12. Bangal VB, Giri PA, Shinde KK, Gavhane BP. Vaginal birth after caesarean section. North Am J Med Sci. 2013;5(2):140-4.

13. Sana A, Kazi A, Iqbal T. Frequency of failed trial of labor and its morbidity in patients with previous one caesarean birth. PJMHS. 2016;10(1):230-2.

14. Shakthi V, Behara RC. Vaginal birth after caesarean delivery. J Obstet Gynaecol India. 2006;56(4):320-3.

15. Jani R, Munshi D. Management of pregnancy with previous lower segment caesarean section in Modern obstetric practice. NHL J Med Sci. 2013;2(2)59-63.

16. Durnwald C, Mercer B. Vaginal birth after caesarean delivery: predicting success, risks of failure. J Matern Fetal Neonatal Med. 2004;15(6):388-93.

17. Doshi HU, Jain RK, Vazirani AA. Prognostic factors for successful vaginal birth after caesarean sectionanalysis of 162 cases. J Obstet Gynecol India. 2010;60(6):498-502.

18. Park JS, Kim KY, Na KH. A study of successful prognostic factors in vaginal birth after caesarean sections. Korean J Obstet Gynecol. 2003;46(11):2209-15. 
19. Abdelazim IA, Elbiaa AAM, Al Kadi M, Yehia AH. Maternal and obstetrical factors associated wih a successful trial of vaginal birth after caesarean section. J turk Ger Gynecol Assoc. 2014;15:245-9.

20. Van der Merwe AM, Thompson JM, Ekeroma AJ. Factors affecting vaginal birth after caesarean section at Middlemore Hospital, Auckland, New Zealand. N Z Med J. 2013;126(1383):49-57.

21. Balachandran L, Vaswani PR, Mogotlane R. Pregnancy outcome in women with previous one caesarean section. J Clin Diagn Res. 2014;8(2):99102.

22. Jinturkar AA, Dongaonkar D. Study of obstetric and fetal outcome of post caesarean section pregnancy at tertiary care center. Intern J Recent Trends Sci Tech. 2014;10(3):530-7.

23. Chaudhari DR, Shinde SM. Clinical profile and outcome of labor in cases following previous caesarean section. Int J Health Sci Res. 2012;2(9):112.

24. Landon MB, Leindecker S, Spong CY, Hauth JC, Bloom S, Varner MW, et al. The MFMU Caesarean Registry: factors affecting the success of trial of labor after previous caesarean delivery. National Institute of Child Health and Human Development Maternal-Fetal Medicine Units Network. Am J Obstet Gynecol. 2005;193:1016-23.

25. Tessmer-Tuck JA, El-Nashar SA, Racek AR, Lohse CM, Famuyide AO, Wick MJ. Predicting vaginal birth after caesarean section: a cohort study. Gynecol Obstet Invest. 2014;77:121-6.
26. Guise JM, Denman MA, Emeis C. Vaginal birth after caesarean, new insights on maternal and neonatal outcomes. Obstet Gynecol. 2010;115:1267-78.

27. Mercer BM, Gilbert S, Landon MB. Labor outcomes with increasing number of prior vaginal births after caesarean delivery. Obstet Gynecol. 2008;111(2 Pt 1):285-91.

28. Hendler I, Bujold E. Effect of prior vaginal delivery or prior vaginal birth after caesarean delivery on obstetric outcomes in women undergoing trial of labor. Obstet Gynecol. 2004;104:273-7.

29. Caughey AB, ShippTD, Repke JT. Trial of labor after caesarean delivery: the effect of previous vaginal delivery. Am J Obstet Gynecol. 1998;179(4):938-41.

30. Gyamfi C, Juhasz G, Gyamfi P, Stone JL. Increased success of trial of labor after previous vaginal birth after caesarean. Obstet Gynecol. 2004;104:715-9.

31. Zelop C, Shipp TD, Repke JT, Cohen A, Lieberman E. Effects of previous vaginal delivery on the risk of uterine rupture during a subsequent trial of labor. Am J Obstet Gynecol. 2000;183:1184-6.

Cite this article as: Ganitha G, Lavanya SG, Balaji Arumugam B. Effect of previous vaginal delivery on success of trial of labor in women with one previous lower segment caesarean section: a prospective study. Int J Reprod Contracept Obstet Gynecol 2016;5:3330-5. 